\title{
ChemComm
}

Check for updates

Cite this: Chem. Commun., 2021, 57,5059

Received 2nd March 2021

Accepted 13th April 2021

DOI: $10.1039 / \mathrm{d} 1 \mathrm{cc} 01152 a$

rsc.li/chemcomm

\section{Mesoporous knitted inverse vulcanised polymers $\dagger$}

\author{
Samuel Petcher, (D) * Bowen Zhang (D) and Tom Hasell (D)*
}

\begin{abstract}
Elemental sulfur is generated in large quantities when crude oil is refined. This elemental sulfur has limited use other than the production of sulfuric acid. Recently, the development of 'inverse vulcanised' polymers has attracted the attention of researchers. These polymers are formed from elemental sulfur and a small molecule alkene. The affinity of sulfur for heavy metals gives these polymers potential for specific adsorption; however, there is a lack of incorporation of high specific surface areas in pure polymers. Herein, we report the first mesoporous polymer generated using inverse vulcanised polymers, with a BET surface area of $236.04 \mathrm{~m}^{2} \mathrm{~g}^{-1}$. We explore the properties of polymers as an absorption medium for potent neurotoxin $\mathrm{Hg}(\mathrm{II})$.
\end{abstract}

Elemental sulfur is produced in large quantities, resulting from the hydrodesulfurisation of crude oil. ${ }^{1}$ The main application of this side product is in the production of sulfuric acid. ${ }^{2}$ Despite the ubiquity of sulfuric acid in the modern industrial processing paradigm, there is still a large excess of sulfur that remains unused. In 2013 Pyun et al. demonstrated that it is possible to form high sulfur content polymers from elemental sulfur and 1,3-diisopropenylbenzene. ${ }^{3}$

Since the publication of Pyun's seminal paper, there have been many other papers that have explored the applications of the polymers produced in this process: energy, ${ }^{4-6}$ optics, ${ }^{7-10}$ water remediation, ${ }^{11-15}$ antimicrobials, ${ }^{16,17}$ coatings, ${ }^{18}$ oilwater separation, ${ }^{19}$ thermal insulation, ${ }^{20}$ gas purification, ${ }^{20}$ and agriculture. ${ }^{21}$ Many of these applications benefit from porosity; however, to date, only a few methods have been explored for the incorporation of porosity into inverse vulcanised polymers.

The first method exploited was demonstrated by Hasell et al., in which they demonstrated the use of supercritical carbon dioxide $\left(\mathrm{scCO}_{2}\right)$ to generate macroporosity, ${ }^{15}$ though

Department of Chemistry, University of Liverpool, Crown Street, Liverpool L69 7ZD, UK. E-mail: Samuel.Petcher@Liverpool.ac.uk,T.Hasell@Liverpool.ac.uk

$\dagger$ Electronic supplementary information (ESI) available. See DOI: 10.1039/ d1cc01152a many of the voids were closed cells. The foamed polymer was then used to absorb mercury chloride $\left(\mathrm{HgCl}_{2}\right)$ from aqueous solution. It was found that the polymer had a higher capacity for $\mathrm{HgCl}_{2}$ than elemental sulfur. The second method was first demonstrated by Parker et al.; they demonstrated the use of a sacrificial sodium chloride porogen $(\mathrm{pNaCl})$ to produce connected macroporosity. ${ }^{22}$ Further research performed in this area has focused on either more foaming or templating methods. ${ }^{14,19-21,23-25}$

One of the most explored applications of porous sulfur polymers is their application in the remediation of mercury contaminated water. Mercury is a persistent and hazardous water pollutant. ${ }^{26,27}$ Sulfur containing materials are particularly suitable for the remediation of mercury contaminated water owing to the soft-soft Lewis acid base interaction that exists between the two elements. ${ }^{28}$

In order to fully realise the potential of sulfur polymers, more effective means of generating porosity must be explored, and one potential route to this is using the hypercrosslinking reaction first reported by Dvankov et al. in the 1970s. In the hypercrosslinking reaction aryl rings are reacted with di or trihaloalkanes to produce a highly crosslinked network via $\mathrm{S}_{\mathrm{N}} \mathrm{Ar}^{20}$ Many creative applications of this process have been explored, for example, in the work performed by Gao $e t a l .{ }^{29}$ These types of reactions produce polymers with interesting characteristics, such as, the ability to swell in solvents that are expected to be non-solvating. This is due to their highly strained polymer network, and the creation of micropore channels that develop around solvent molecules.

Herein, we report the first attempt in applying this type of reaction to inverse vulcanised polymers (Fig. 1). Poly[s-(ran)styrene] was prepared as previously reported by Pyun et $a l^{3}$ Subsequently, poly[s-(ran)-styrene] $(2 \mathrm{~g})$ was weighed in a dry $100 \mathrm{~mL}$ round bottom flask and $40 \mathrm{~mL}$ of dry chloroform was added. The solution was stirred at $800 \mathrm{rpm}$ with a magnetic stirrer for 2 hours. A cloudy suspension formed. $\mathrm{AlCl}_{3}(2 \mathrm{~g}, 15 \mathrm{mmol}$ ) was added to the round bottom flask. Immediately a light red suspension formed, which darkened within 10 minutes. After 2 hours, 
1)<smiles></smiles><smiles>C=Cc1ccccc1</smiles>
$120^{\circ} \mathrm{C}, \mathrm{N}_{2}$ $8 \mathrm{~h}$

2)

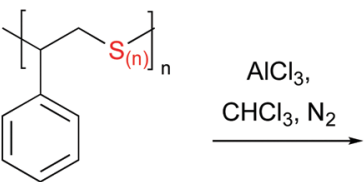<smiles>CCSCC(C)C</smiles>

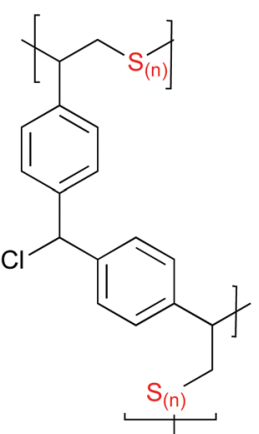

Fig. 1 Reaction scheme for the generation of a mesoporous inverse vulcanised polymer through post synthetic crosslinking. Briefly, sulfur and styrene were mixed and heated at $130{ }^{\circ} \mathrm{C}$ under nitrogen to polymerise in step one, before $\mathrm{AlCl}_{3}$ and chloroform were added, at $50{ }^{\circ} \mathrm{C}$ to induce crosslinking in the second step.

the reaction was quenched with methanol and extracted with methanol and then chloroform to yield a brown powder. The powder was vacuum dried.

Often, polymers that are post-synthetically modified by processes such as these are imparted with a large specific surface area. Previous reports have demonstrated specific surface areas exceeding $3000 \mathrm{~m}^{2} \mathrm{~g}^{-1} \cdot{ }^{30}$ However, a large fraction of micropores was not generated during this process. This is most likely owing to the very high $(70 \% \mathrm{w} / \mathrm{w})$ sulfur content of the polymers. This lowers the 'rigidity' of the final structure and likely leads to pore collapse during the process. Furthermore, the low density of phenyl rings is likely to reduce the degree of crosslinking that occurs. However, this does not necessarily mean that these polymers are lacking in application.

Lee et al. previously found that two very similar activated carbon materials perform differently for the absorption of heavy metal ions depending on their pore size distribution. ${ }^{31}$ They found that a purely microporous sample was outperformed by a sample that contained mesopores. Fig. 2a displays a micrograph generated using scanning electron microscopy (SEM). The micrograph shows the typical 'cauliflower' macroporosity that is usually generated in precipitation polymerisation.

Fig. 2 b demonstrates the complementary technique: energydispersive X-ray spectroscopy (EDX). The produced elemental map demonstrates the sulfur rich nature of the produced polymeric material (blue). The exact elemental composition of the polymer was found to be (C: $37.23 \%, \mathrm{H}: 2.48 \%$, and $\mathrm{S}$ : $51.50 \%$ ) by combustion analysis. There was no signal for $\mathrm{Al}$ detected in the spectrum produced.

The application of these materials in mercury absorption was investigated. Experiments were conducted by placing $20 \mathrm{mg}$ of polymer into a centrifuge tube and dispensing a required amount of aqueous mercury solution. The samples

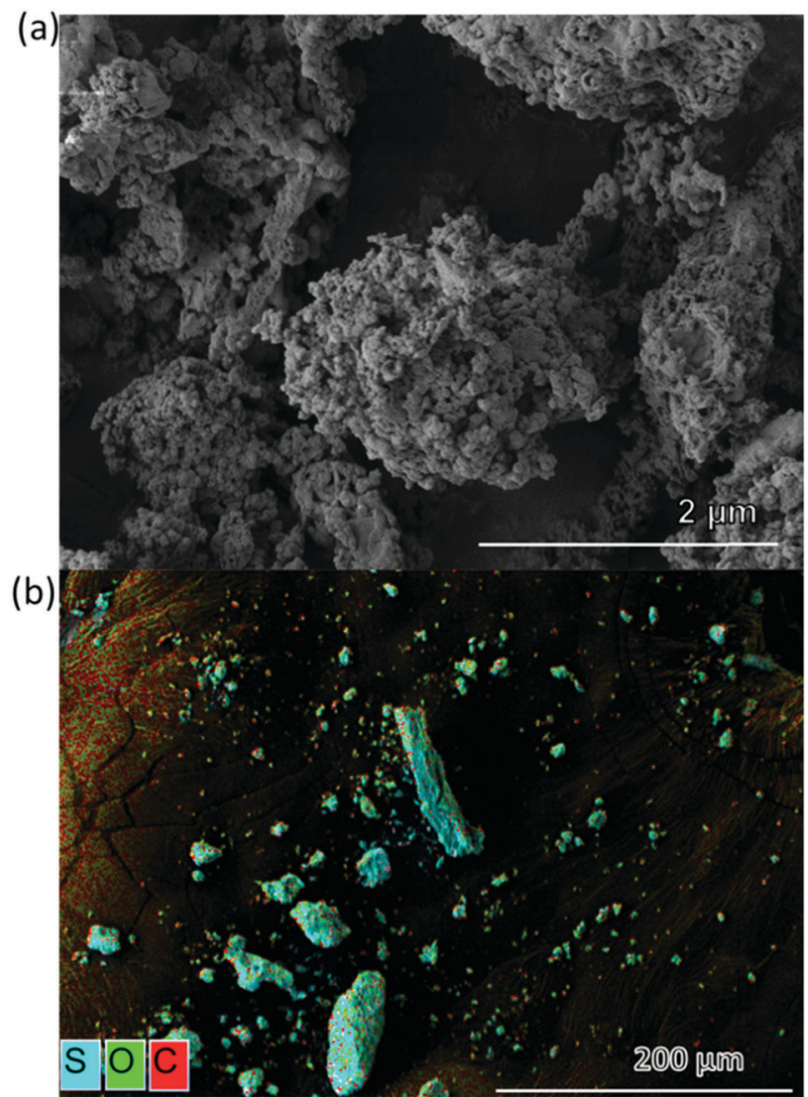

Fig. 2 (a) Micrograph demonstrating the apparent mesoporosity that was generated during the Freidel-Crafts reaction. (b) EDX spectroscopy map of the produced polymer SHCP-01, demonstrating the high sulfur content nature of the material.

were subsequently sonicated for 5 minutes and then placed on a rotary stirrer for 24 hours.

Fig. 3a demonstrates the Langmuir isotherm obtained for the absorption of $\mathrm{HgCl}_{2}$ from solution that was obtained using the data gathered in the experiment.

The capacity of the material found was to be $215.9 \mathrm{mg} \mathrm{g}^{-1}$. This is comparable to activated carbons, MOFs and Zeolites. It is apparent that the sample has a high affinity $\left(K_{\mathrm{d}}=0.48\right)$, and this is important because the current need for absorption media in mercury contaminated waters is for materials that are capable of reducing the mercury concentration as low as possible, ideally eliminating it completely. This is because there is no safe amount for mercury in solution. Current World Health Organisation recommendations are that drinking water should not contain more than 6 ppb mercury. ${ }^{32}$

Previous reports for porous inverse vulcanised polymers usually exhibit low capacities. An example of this would be the previously mentioned $\mathrm{pNaCl}$ polymer, that had a capacity of $2.27 \mathrm{mg} \mathrm{g}^{-1} .^{11}$ SHCP-01 has almost 100 times the capacity of this material. An example of a non-porous sulfur polymer, such as that reported by Zhang et al. had a capacity of $1.60 \mathrm{mg} \mathrm{g}^{-1} .^{33}$

When the material was analysed via $\mathrm{N}_{2}$ gas sorption, it demonstrated a Type $\mathrm{V}$ absorption isotherm. This type of isotherm is characteristic of mesoporous solids. The material 
(a)

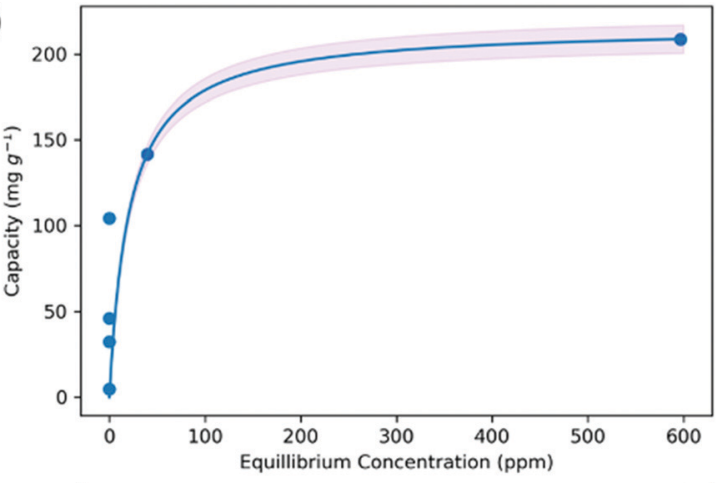

(b)

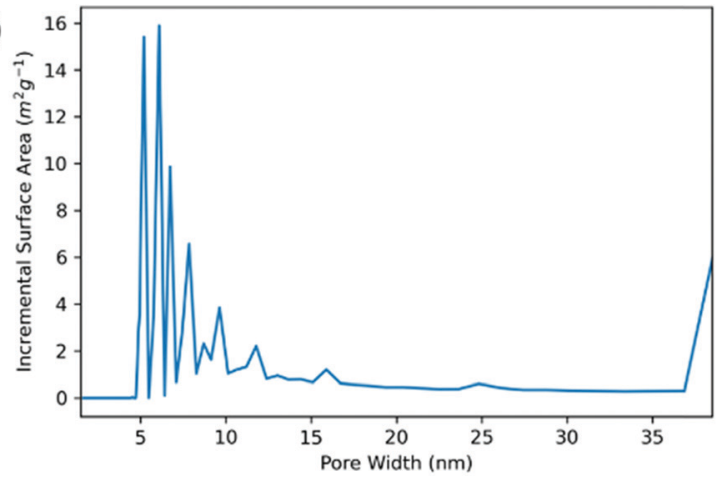

Fig. 3 (a) Adsorption isotherm for $\mathrm{HgCl}_{2}$ from solution fitted to a Langmuir model. (b) The pore size distribution of the produced polymer, as derived from the $\mathrm{N}_{2}$ isotherm highlighting the mesoporous nature of the produced polymer.

displays the characteristic convex curve and a hysteresis loop that is exhibited when capillary condensation occurs in the pores of the sample (ESI $\dagger$ S1-2). The BET specific surface area is $236.04 \mathrm{~m}^{2} \mathrm{~g}^{-1}$ (ESI $\left.\dagger \mathrm{S} 1\right)$. This is significant in the context of inverse vulcanised polymers as previously reported in the work by Petcher $e t$ al. that employed the use of surface area characterisation for a polymer produced using a porogen and found a surface area of $15.89 \mathrm{~m}^{2} \mathrm{~g}^{-1} \cdot{ }^{11}$ The knitted polymer reported here has $\sim 15$ times the surface area of that mentioned in the previous report.

Whilst the specific surface area is relatively low when compared to materials such as porous molecular crystals, MOFs, COFs, and HOFs, it is not the key determinant in the absorption parameter of the material. As previously discussed, Lee $e t$ al. found that the mesoporous activated carbons were far more effective for the adsorption of mercury than those of the microporous samples. ${ }^{31}$

Therefore, it is likely that the optimum pore size and chemical composition of materials for absorption of mercury are not simply a combination of highest surface area, and highest sulfur content but a more nuanced series of properties, such as, hydrophilicity, mesoporosity, and thiol content.

Having performed tests to assess the viability of the adsorbent we employed (SHCP-01) for the removal of $\mathrm{HgCl}_{2}$ at relatively high $(>1 \mathrm{ppm})$ concentrations, the viability of the sorbent to remove forms of mercury that are encountered in environmental situations was then assessed next. It is well reported that one of the forms of mercury that is encountered in the environment is methylmercury chloride. This chemical is often found accumulated in soils. We found that compared to the control, SHCP-01 was able to remove over $99 \%$ of methylmercury chloride from aqueous solution (ESI $\dagger$ S10). It is important to note that the remaining $\mathrm{Hg}$ in solution here is approaching the detection limits of the instrumentation (ICP-OES).

Demonstration of removal of solutions with concentrations above $1 \mathrm{ppm}$, even with more environmentally relevant concentrations of mercury does not, however, prove the efficacy of the adsorbent in removing mercury from the solution in a true 'real world' scenario. In this type of scenario there are competing metal ions, and concentrations are usually below $1 \mathrm{ppm}$. As a result of this, we tested the ability of the material to remove mercury from a simulated contaminated water stream at a concentration below $1 \mathrm{ppm}$.

The simulated water contained a variety of metal ions, such as, Ni, As, and Cd amongst others (Fig. 4a). It was found that the polymer was highly selective for $\mathrm{Hg}$ and $\mathrm{Sb}$. Other metals were taken into the polymer at varying levels of efficacy. The solutions were analysed via ICP-MS which is able to detect concentrations as low as $0.001 \mathrm{ppb}$. Overall, it was found that the polymer is able to reduce the concentration of mercury in solution by above $99 \%$, given $<10 \mathrm{ppb}$ concentrations in the presence of competing metal ions at over 100 times the concentration of mercury. This experiment confirms the excellent selectivity of the material for aqueous $\mathrm{Hg}$.

(a)

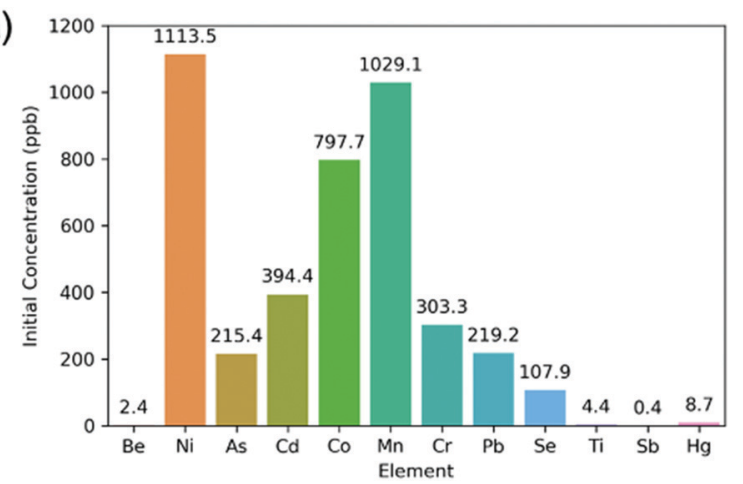

(b)

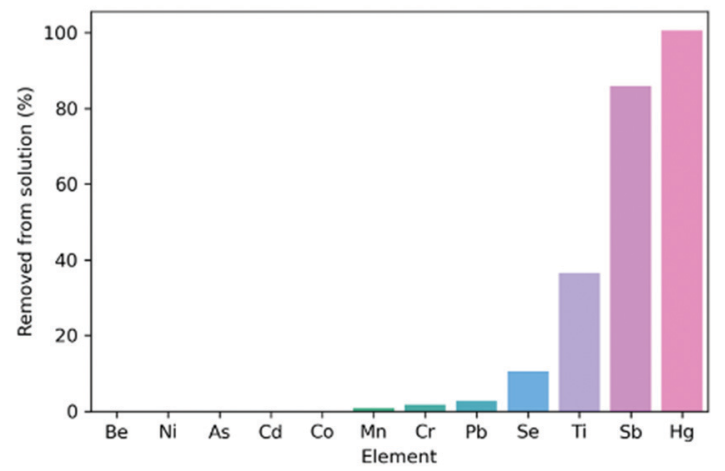

Fig. 4 (a) Initial concentration of metal ions in the simulated river water experiment. (b) Percentage of metal ions removed by SHCP-01 in the simulated river water experiment. 
In conclusion, the reaction of poly[s-(ran)-styrne] with $\mathrm{CHCl}_{3}$, catalysed by $\mathrm{AlCl}_{3}$, was reported for the first time. Unique polymers were produced with high capacity and affinity for aqueous $\mathrm{HgCl}_{2}$. These polymers are of particular interest in the sulfur polymer research field because of their high specific surface area and unique characteristic of mesoporosity which has not been reported elsewhere, as we know.

Furthermore, there has been recent interest in the uptake of mercury from water using inverse vulcanised polymers. The materials reported here possess the highest capacity for mercury that has been reported for a pure inverse vulcanised polymer, without carbonisation or coating onto a porous support matrix.

The materials were demonstrated to be effective at high concentrations $(>500 \mathrm{ppm})$ whilst retaining efficacy in 'real world' low concentration situations ( $<100 \mathrm{ppb})$.

Further research in this exciting new area opens the potential for the generation of micropores in inverse vulcanised polymers, by tuning of the sulfur content and hence the rigidity of the polymer chain. It should also be possible to further tune the functionality and hydrophilicity of the produced polymers by varying the crosslinking components. There is the open possibility of using green methods like mechanochemistry to produce the polymers. There is also potential for the polymers to be used in the absorption of other 'soft' metal ions, gas separations and storage and potentially in $\mathrm{Li}-\mathrm{S}$ batteries.

We thank S. Moss for ICP analysis and A. Lunt for pXRD. TH is a Royal Society University Research Fellow.

\section{Conflicts of interest}

There are no conflicts to declare.

\section{References}

1 P. Grange, Catal. Rev. Eng., 1980, 21, 135-181.

2 W. Moeller and K. Winkler, J. Air Pollut. Control Assoc., 1968, 18, 324-325.

3 W. J. Chung, J. J. Griebel, E. T. Kim, H. Yoon, A. G. Simmonds, H. J. Ji, P. T. Dirlam, R. S. Glass, J. J. Wie, N. A. Nguyen, B. W. Guralnick, J. Park, A. Somogyi, P. Theato, M. E. Mackay, Y. E. Sung, K. Char and J. Pyun, Nat. Chem., 2013, 5, 518-524.

4 F. Wu, S. Chen, V. Srot, Y. Huang, S. K. Sinha, P. A. van Aken, J. Maier and Y. Yu, Adv. Mater., 2018, 30, 1-8.

5 H. Kang, H. Kim and M. J. Park, Adv. Energy Mater., 2018, 8, 1-9.

6 A. Hoefling, D. T. Nguyen, P. Partovi-Azar, D. Sebastiani, P. Theato, S. W. Song and Y. J. Lee, Chem. Mater., 2018, 30, 2915-2923.

7 L. E. Anderson, T. S. Kleine, Y. Zhang, D. D. Phan, S. Namnabat, E. A. LaVilla, K. M. Konopka, L. Ruiz Diaz, M. S. Manchester, J. Schwiegerling, R. S. Glass, M. E. Mackay, K. Char, R. A. Norwood and J. Pyun, ACS Macro Lett., 2017, 6, 500-504.

8 J. J. Griebel, R. S. Glass, K. Char and J. Pyun, Prog. Polym. Sci., 2016, 58, 90-125.

9 J. J. Griebel, S. Namnabat, E. T. Kim, R. Himmelhuber, D. H. Moronta, W. J. Chung, A. G. Simmonds, K. J. Kim, J. Van
Der Laan, N. A. Nguyen, E. L. Dereniak, M. E. MacKay, K. Char, R. S. Glass, R. A. Norwood and J. Pyun, Adv. Mater., 2014, 26, 3014-3018.

10 J. J. Griebel, S. Namnabat, E. T. Kim, R. Himmelhuber, D. H. Moronta, W. J. Chung, A. G. Simmonds, K.-J. Kim, J. van der Laan, N. A. Nguyen, E. L. Dereniak, M. E. Mackay, K. Char, R. S. Glass, R. A. Norwood and J. Pyun, Adv. Mater., 2014, 26, 3014-3018.

11 S. Petcher, D. J. Parker and T. Hasell, Environ. Sci.: Water Res. Technol., 2019, 5, 2142-2149.

12 M. P. Crockett, A. M. Evans, M. J. H. Worthington, I. S. Albuquerque, A. D. Slattery, C. T. Gibson, J. A. Campbell, D. A. Lewis, G. J. L. Bernardes and J. M. Chalker, Angew. Chem., Int. Ed., 2016, 55, 1714-1718.

13 J.-S. M. Lee, D. J. Parker, A. I. Cooper and T. Hasell, J. Mater. Chem. A, 2017, 5, 18603-18609.

14 A. D. Tikoalu, N. A. Lundquist and J. M. Chalker, Adv. Sustainable Syst., 2020, 4, 1-9.

15 T. Hasell, D. J. Parker, H. A. Jones, T. McAllister and S. M. Howdle, Chem. Commun., 2016, 52, 5383-5386.

16 Z. Deng, A. Hoefling, P. Théato and K. Lienkamp, Macromol. Chem. Phys., 2018, 219, 1700497.

17 J. A. Smith, R. Mulhall, S. Goodman, G. Fleming, H. Allison, R. Raval and T. Hasell, ACS Omega, 2020, 5, 5229-5234.

$18 \mathrm{X}$. Wu, J. A. Smith, S. Petcher, B. Zhang, D. J. Parker, J. M. Griffin and T. Hasell, Nat. Commun., 2019, 10, 647.

19 N. A. Lundquist, M. J. H. Worthington, N. Adamson, C. T. Gibson, M. R. Johnston, A. V. Ellis and J. M. Chalker, RSC Adv., 2018, 8, 1232-1236.

20 A. M. Abraham, S. V. Kumar and S. M. Alhassan, Chem. Eng. J., 2018, 332, 1-7.

21 M. Mann, J. E. Kruger, F. Andari, J. McErlean, J. R. Gascooke, J. A. Smith, M. J. H. Worthington, C. C. C. McKinley, J. A. Campbell, D. A. Lewis, T. Hasell, M. V. Perkins and J. M. Chalker, Org. Biomol. Chem., 2019, 17, 1929-1936.

22 D. J. Parker, H. A. Jones, S. Petcher, L. Cervini, J. M. Griffin, R. Akhtar and T. Hasell, J. Mater. Chem. A, 2017, 5, 11682-11692.

23 M. J. H. Worthington, C. J. Shearer, L. J. Esdaile, J. A. Campbell, C. T. Gibson, S. K. Legg, Y. Yin, N. A. Lundquist, J. R. Gascooke, I. S. Albuquerque, J. G. Shapter, G. G. Andersson, D. A. Lewis, G. J. L. Bernardes and J. M. Chalker, Adv. Sustainable Syst., 2018, 2, 1800024.

24 M. J. H. Worthington, R. L. Kucera, I. S. Albuquerque, C. T. Gibson, A. Sibley, A. D. Slattery, J. A. Campbell, S. F. K. Alboaiji, K. A. Muller, J. Young, N. Adamson, J. R. Gascooke, D. Jampaiah, Y. M. Sabri, S. K. Bhargava, S. J. Ippolito, D. A. Lewis, J. S. Quinton, A. V. Ellis, A. Johs, G. J. L. Bernardes and J. M. Chalker, Chem. - Eur. J., 2017, 23, 16219-16230.

25 M. J. H. Worthington, C. J. Shearer, L. J. Esdaile, J. A. Campbell, C. T. Gibson, S. K. Legg, Y. Yin, N. A. Lundquist, J. R. Gascooke, I. S. Albuquerque, J. G. Shapter, G. G. Andersson, D. A. Lewis, G. J. L. Bernardes and J. M. Chalker, Adv. Sustainable Syst., 2018, $2,1800024$.

26 L. Järup, Br. Med. Bull., 2003, 68, 167-182.

27 R. Kessler, Environ. Health Perspect., 2013, 121.

28 R. G. Pearson, J. Am. Chem. Soc., 1963, 85, 3533-3539.

29 H. Gao, L. Ding and H. Bai, L. L.- ChemSusChem and undefined 2017, Wiley Online Libr.

30 J. Huang and S. R. Turner, Polym. Rev., 2018, 58, 1-41.

31 J. S. M. Lee, D. J. Parker, A. I. Cooper and T. Hasell, J. Mater. Chem. A, 2017, 5, 18603-18609.

32 W. H. O. WHO, Who, 2005, WHO/SDE/WS, WHO/SDE/WSH/05.08/ 10.

33 B. Zhang, L. J. Dodd, P. Yan and T. Hasell, React. Funct. Polym., 2021, 161, 104865. 